\title{
IMPLICAÇÕES LINGUÍSTICAS NA TEORIA DA TRADUÇÃO COMO COMPREENSÃO DE STEINER
}

\section{LANGUAGE IMPLICATIONS IN THE STEINER'S THEORY UNDERSTANDING AS TRANSLATION}

\author{
Naaman Mendes Lataliza \\ Universidade Federal de Ouro Preto \\ Ouro Preto, Minas Gerais, Brasil.
}

RESUMO: Em algumas teorias, o ato de traduzir vai além do enunciar numa outra língua o que foi enunciado numa língua fonte: acontece também no interior de uma língua. Jakobson (1959) é um dos nomes que toca nessa questão, propondo o que ele chama de tradução intralingual. Quem, no entanto, se aprofunda nessa problemática é George Steiner (1992), no seu livro Depois de Babel, em cujo primeiro capítulo, denominado A compreensão como tradução, há a exposição do fato de que, para que haja compreensão, é necessária a recriação do significado de maneira interpretativa, e, tendo a interpretação um resíduo privado, construído a partir de memórias, da identidade psicológica e somática, há uma proliferação de nuances de significados que tornam a expressão pura inadmissível. Assim, para o autor, a interpretação seria um processo de tradução intralingual. Partindo da ideia de que compreender é traduzir, o presente trabalho objetiva fazer um esboço de algumas teorias linguísticas que estão imbricadas no texto de Steiner (1992) explícita ou implicitamente. Ainda que o autor se valha majoritariamente de exemplos literários, há, em seu texto, uma argumentação alicerçada em teorias puramente linguísticas, por isso é interessante expô-las e mostrar como elas corroboram a tese desse autor.

PALAVRAS-CHAVE: Steiner; Tradução intralingual; Linguística

\begin{abstract}
In some theories, the act of translating overcomes the act of enunciating in a foreign language what had been said in a source language: it also happens inside of a language. Jakobson (1959) is one of the names who mentions this phenomenon, stating what he calls intralingual translation. George Steiner (1992), however, deepens this issue in his book After Babel, in whose first
\end{abstract}


chapter - named Understanding as translation -, there is the exhibition of the fact that, in order to be understood, a recreation of the meaning in an interpretative way is necessary, and, since the interpretation is a private residue, built upon memories, psychological and somatic identity, there is a proliferation of nuances of meanings which convey a pure expression as unallowable. Thus, for the latter author, the interpretation is an intralingual translation process. Keeping in mind that understanding is translating, the present paper aims to sketch some linguistic theories present in Steiner (1992) explicitly or implicitly. Although the author mostly makes uses of examples from literature, his arguments are based on pure linguistic theories, so it is interesting to expose them and to show how they validate his thesis.

KEYWORDS: Steiner; Intralingual translation; Linguistics 


\section{INTRODUÇÃO}

Um dos grandes nomes da linguística que atuou nos estudos de tradução e que pôs em jogo o fato de haver tradução dentro de uma mesma comunidade linguística foi Roman Jakobson (1959), que, em seu trabalho Aspectos Linguísticos da Tradução, apresenta a noção de tradução intralingual e mostra que sujeitos que compartilham uma mesma língua também estão fadados a passar por processos tradutórios. Para o linguista, o significado das palavras é um fato semiótico, portanto, não é necessário que um sujeito precise experimentar, vivenciar ou ter um contato direto com qualquer coisa no mundo para que possa apreender seu sentido, e, se assim fosse, traduzir seria impossível. Os indivíduos compreendem significados de quaisquer termos no mundo e sabem em que contextos podem empregá-los devido ao fato de que se constroem sentidos a partir de relações linguísticas e cognitivas. A capacidade dos indivíduos de usar a linguagem permite que produzam fenômenos semióticos e, assim, interpretem diferentes signos linguísticos.

Para que um sujeito compreenda uma palavra nova, basta que ele recorra a uma série de outros signos linguísticos, pois o significado de qualquer signo é a sua tradução em outros signos alternativos mais explícitos. Assim sendo, o autor propõe que um signo pode ser traduzido de três diferentes maneiras: (1) em outros signos da mesma língua (tradução intralingual ou reformulação); (2) em signos de outra língua (interlíngual); e (3) em signos não verbais (intersemiótica ou transmutação). Desse modo, o linguista põe em jogo o fato de haver tradução numa mesma língua e dá a esse fenômeno o nome de tradução intralingual. Em termos práticos, para Jakobson (1959), a tradução numa mesma língua nada mais é que uma reformulação. Ainda que não haja correspondência total entre os signos linguísticos, é possível, por exemplo, substituir, no português brasileiro, homem não casado por homem solteiro sem grandes problemas, a depender do contexto. Outro exemplo prático e que ilustra bem a ideia do linguista é a paráfrase, ou seja, a explicação ou interpretação de qualquer texto com outras palavras, como, por exemplo, a transformação da frase o avião chegou com atraso em algo como o avião chegou atrasado.

Jakobson (1959), no entanto, não se aprofunda na questão da tradução intralingual, apenas discute esse fenômeno nos casos mais explícitos e óbvios citados anteriormente, nos quais reformulamos nossos enunciados. Quem se aproveita dessa seara e abre novas perspectivas para a tradução intralingual é Steiner, em 1975, no seu trabalho Depois de Babel, mais precisamente, no capítulo A compreensão como tradução.

Mitos, por serem mais poéticos e apelativos que teorias construídas com dados e raciocínios, quase nunca são descartados dos imaginários sociais e são aceitos como uma opção à verdade. Um mito muito caro aos estudos da tradução é o da Torre De Babel, presente no livro Gênesis, em cujo primeiro versículo há a afirmação de que em toda a terra havia uma mesma língua e uma mesma fala. Nessa passagem bíblica, narra-se construção de uma torre, na planície de Sinear, que atingiria os céus, mas Deus, por se sentir desafiado pelos humanos, desceu à 
terra e confundiu a linguagem humana, para que um não entendesse a língua do outro. Nesse mito, há um divisor de águas: num momento, havia uma língua una, pura, coesa; noutro, essa língua se desfaz, e todos passam a se comunicar com uma língua própria, não há mais coesão. $\mathrm{E}$, por conta disso, nasce o trabalho do tradutor.

Esse mito, então, inicia a tarefa do tradutor: a partir do momento em que línguas começam a coexistir, há a necessidade de comunicação entre pessoas que estão imersas em sistemas linguísticos diferentes. Para Steiner (1992), no entanto, o problema de babel apenas confirmou e exteriorizou a tarefa do tradutor, mas não a iniciou. A maldição enviada por Deus para impedir que houvesse entendimento entre os humanos não desencadeou a incompreensão, ela já existia na língua primeira. $\mathrm{O}$ autor, então, vai além do que Jakobson propôs como tradução intralinguística e afirma que ocorre um ato de tradução sempre que se recebe uma mensagem verbal de qualquer outro ser humano.

Para exemplificar sua tese, Steiner (1992) vale-se, na maior parte do tempo, de exemplos literários (Cimbelono, de Shakespeare, principalmente). No entanto, há em seu texto afirmações de bases puramente linguísticas, sendo uma das mais recorrentes a Sociolinguística. Desse modo, é interessante buscar compreender como as teorias desse campo de estudos corroboram a ideia de que compreender é traduzir.

\section{CONTRIBUIÇÕES DA SOCIOLINGUÍSTICA}

Uma das bases sobre as quais Steiner (1992) se apoia para afirmar que compreender é traduzir é a Sociolinguística, parte da linguística cuja tarefa é revelar, na medida do possível, a covariação entre os fenômenos linguísticos e sociais e, eventualmente, estabelecer uma relação de causa e efeito (BELINE, 2011). Steiner (1992) parte de um conceito básico da sociolinguística: variedades regionais e dialetais. $\mathrm{O}$ autor afirma que amplos terrenos físicos engendram diferentes formas de falar, o que faz com que pessoas que moram em lugares distantes, ainda que oficialmente participantes de um mesmo sistema linguístico, traduzam-se. É fato que no português brasileiro, por exemplo, são detectadas diferenças em todos os níveis gramaticais na fala de moradores do Amazonas e na de moradores de Rio Grande do Sul. Em ambos os lugares fala-se o português brasileiro, mas são culturas diferentes com aspectos sócio-históricos diferentes, o que faz com que, por exemplo, o léxico mude, além de aspectos sintáticos, semânticos e, principalmente, fonéticos. Essa é, de acordo com Steiner (1992), a disparidade mais óbvia que faz com que haja tradução intralingual.

Comparar dois lugares tão distantes um do outro torna a questão bem mais simples do que parece. Afunilando um pouco mais o foco, é possível perceber que, como afirma Steiner (1992, p. 57), comunidades complexas implicam disparidades linguísticas ainda mais sutis, relacionadas, por exemplo, ao status social, aos valores, às atividades profissionais, à idade, ao sexo, etc. Ou seja, não 
é preciso, nesse caso, comparar Amazonas com Rio Grande do Sul. Uma só cidade compreende diferentes "línguas portuguesas".

Steiner (1992) se debruça sobre a questão das disparidades na fala de homens e mulheres, fato que toca na questão do status social. Ao fazer isso, ele explora a seara da variação linguística que William Labov (o cientista mais conhecido das teorias variacionistas) tanto explorou (BELINE, 2011). Afirmar que homens e mulheres falam diferentemente, na perspectiva sociolinguística, não é entrar na questão fisiológica, ou seja, homens falarem num tom mais grave e mulheres num mais agudo. A sociolinguística busca responder em que limite e de que forma que esses fenômenos linguísticos estão correlacionados ao gênero/sexo do falante. Na verdade, a mudança na fala de homens e mulheres apenas reflete diferenças no processo de socialização e nos papéis que cada comunidade atribui a homens e mulheres. Em geral, as mulheres ocidentais tendem a ser linguisticamente mais conservadores ou mais orientadas para variantes de prestígio em algumas comunidades de fala, fato que é resultado de um processo diferenciado de socialização de homens e mulheres e da dinâmica de mobilidade social que caracteriza cada comunidade de fala: homens estão mais sujeitos à influência do prestígio encoberto das formas linguísticas do que as mulheres, dado que eles possuem mais mobilidade social e maior participação em grupos sociais mais fechados. Outro fator: mulheres tendem a resguardar a face e manifestar um comportamento que garanta sua aceitação social, uma vez que a posição social da mulher na sociedade, geralmente, está menos assegurada que a do homem - é válido lembrar que qualquer explicação das diferenças linguísticas deve ser relativizada em função do grupo social considerado (PAIVA, 2004, p. 34). Steiner (1992), então, parte de disparidades óbvias, como as regionais, e toca em questões mais sutis, como a diferença na fala de homens e mulheres decorrente de questões sociais.

$\mathrm{O}$ autor toca, ainda, nas disparidades linguísticas usadas por diferentes classes sociais e grupos étnicos para afirmar suas identidades ou se confrontarem. $\mathrm{O}$ atual vernáculo negro americano é um bom exemplo dessa disparidade causada por questões identitárias e de confronto. Essa norma linguística é claramente diferente do inglês padrão em todos os níveis gramaticais, e há uma explicação datada e histórica para isso. $\mathrm{O}$ inglês padrão foi imposto aos negros escravizados que foram arrancados de suas culturas e de suas línguas e que foram levados contra a própria vontade para um mundo em que eles eram oprimidos e no qual a língua materna deles não fazia mais sentido. Para bell hooks (2008), autora, feminista e ativista social estadunidense, essa norma padrão era o som do massacre e da conquista, uma arma de opressão e humilhação. No entanto, os africanos escravizados subvertem a língua à qual são expostos: eles ouvem o inglês padrão como a língua do opressor, mas re-ouvem-na como uma potencial forma de resistência. Eles percebem a necessidade de se aprender a língua daqueles que oprimiam para recuperar o poder no contexto de dominação, para a comunicação entre os oprimidos (que, muitas vezes, nem falavam a mesma língua). $\mathrm{O}$ interessante é que essa apropriação da língua não ocorreu de forma passiva: houve a subversão, a reinvenção do idioma: 
O povo negro escravizado pegou pedaços partidos do inglês e fez deles uma contralíngua. Eles colocaram junto suas palavras de tal maneira que o colonizador tivesse de repensar o significado da língua inglesa. (HOOKS, 2008, p. 859)

Nas bocas de africanos negros, o inglês foi alterado, transformado, passou por deslizes semânticos e tornou-se uma fala diferente. Esse exemplo mostra que, mesmo dentro de uma comunidade de fala institucionalmente perpassada por uma só língua, as funções conflituosas da fala superam as funções de comunicação genuína (STEINER, 1992, p. 57).

Por fim, Steiner (1992) menciona o resíduo comunicativo privado: o idioleto. Esse termo da sociolinguística diz respeito ao conjunto de enunciados produzidos por uma só pessoa e às constantes linguísticas que lhe são subjacentes. $\mathrm{O}$ idioleto era a prova final de que Steiner precisava para comprovar sua tese de que todo ato comunicativo é perpassado pela tradução: há variação não somente de um país a outro, de uma região a outra, de uma aldeia a outra, de uma classe social a outra, mas também de uma pessoa a outra. Assim, partindo da perspectiva puramente sociolinguística de que a língua é inerentemente variável, além de ser um produto cultural e social, Steiner (1992) afirma que, ao receber uma mensagem verbal, todo ser humano realiza um ato de tradução.

O tempo, a distância, disparidades de ponto de vista ou de referência pressuposta tornam esse ato mais ou menos difícil. Onde a dificuldade é suficientemente grande, o processo passa do reflexo para a técnica consciente. (STEINER, 1992, p. 71)

Além das questões sociais, Steiner (1992) toca também em teorias semiolinguísticas. A próxima parte deste trabalho, portanto, é uma tentativa de esboço de como essas teorias contribuem com a tese desse autor.

\section{O SIGNIFICADO DERRAPA SOBRE O SIGNIFICANTE}

\subsection{A QUESTÃO É MAIS ANTIGA DO QUE PARECE}

Em certo momento de seu texto, Steiner (1992) afirma que outro fator que faz com que haja tradução numa mesma comunidade linguística é a polissemia do signo, ou seja, a possibilidade de a mesma palavra significar coisas diferentes, com tais diferenças variando entre nuanças e antíteses. Antes de entrar em teorias linguísticas sobre as quais essa afirmação está alicerçada, é interessante pontuar que essa discussão não é nova e muito menos foi inaugurada pelos estudos linguísticos. A noção de perspectivismo (ou seja, a coisa é isso ou aquilo a partir de determinada perspectiva) já era discutida pelo sofista Protágoras, o qual afirma que a suposta verdade sobre as coisas não é dada de modo natural, pois tudo estaria à mercê de pontos de vista. Isso implica também o fato de que palavras iguais podem ter significados totalmente diferentes a depender do contexto em 
que elas são empregadas e de quem as emprega, o que faz com que não seja possível afirmar quem é que está com a razão, ou seja, quem é que detém o significado real da palavra:

[...] E, ao fazeres esta distinção, verás a outra lei para os mortais: nada é em todas as circunstâncias nem decente nem vergonhoso, mas o momento oportuno toma as coisas e torna-as vergonhosas e transforma-as e torna-as decentes. (DISSOI LOGOI apud SOUSA e PINTO, 2005, p. 290)

Em função de um momento oportuno e dos conhecimentos partilhados nos imaginários sociais, especula-se sobre o que é preferível e adequado, sem poder se definir o que é verdadeiro. Apesar de não haver espaço neste trabalho para discutirmos a questão do pensamento sofístico, acreditamos ser interessante citar o alicerce de tantas teorias atuais. Desse modo, partimos para algumas discussões de âmbito linguístico que tocam na questão da polissemia das palavras, fato que faz com que, de acordo com Steiner (1992), discursos se tornem cheios de palavras fantasmas, tendo sentidos contrários ou nada significando.

\subsection{A ARBITRARIEDADE DO SIGNO}

Saussure (1995), em seu Curso de Linguística Geral, afirma que a língua está longe de ser algo relacionado a nomenclaturas, ou seja, uma lista de termos que correspondem às coisas do mundo. Se assim fosse, seria preciso admitir que havia ideias complementares preexistentes às palavras e que haveria um vínculo unindo um nome às coisas. É dessa maneira que a ideia de significado é construída na mitologia judaico-cristã, bem depois da cena da criação:

(...) e disse o Senhor Deus: Não é bom que o homem esteja só; far-lhe-ei uma adjutora que esteja como diante dele. Havendo pois o senhor Deus formado da terra todo animal do campo e toda a ave dos céus, os trouxe a Adão, para este ver como lhes chamaria; e tudo o que Adão chamou a toda a alma vivente, isso foi o seu nome. (GÊN, II, 18-20)

Nesse trecho bíblico, estabelece-se uma relação entre os nomes e as coisas do mundo, fato posto por Saussure (1995) como simplista e criticável em numerosos aspectos.

Saussure (1995) propõe que os signos linguísticos não são a união entre a palavra e uma coisa, mas, sim, entre um conceito e uma imagem acústica. A imagem acústica (significante) não diz respeito ao som, questão puramente física, mas sim à impressão psíquica que é construída na mente do falante por meio desse som. Já o conceito (significado) não é a realidade que ele designa, mas a sua representação; é o que quem emprega o signo entende por ele. Essas duas faces que compõem o signo linguístico estão intimamente ligadas e uma reclama a outra. Assim, a imagem acústica /meza/ não evoca uma mesa particular, mas a 
ideia geral de mesa, sendo abstraídas as características particulares de cada mesa (FIORIN, 2011, p. 59).

Um dos princípios dos signos linguísticos propostos por Saussure (1995) o é da arbitrariedade do signo. Para o linguista, o laço que une o significante ao significado é totalmente arbitrário, não havendo motivações naturais para tal. Prevendo possíveis críticas, Saussure se adianta e afirma que mesmo as onomatopeias que poderiam ser consideradas como signos totalmente motivados são, na verdade, arbitrárias. As onomatopeias se encaixam nos padrões fonéticos e morfológicos das línguas e elas não passam de imitações aproximativas e convencionais de certos ruídos: a onomatopeia para o latido em inglês é woof, ao passo que, no português brasileiro, é $a u-a u$.

Ao propor a teoria da arbitrariedade dos signos, Saussure (1995) põe em jogo o fato de não se poder acessar as coisas do mundo por meio da linguagem, já que o signo é de caráter puramente cognitivo e é sua representação que nos dá o testemunho de nossos sentidos. Assim, as línguas não são nomenclaturas que se aplicam a uma realidade, são modos de interpretar o mundo. Partindo dessa hipótese, é possível afirmar que a construção dos sentidos é um fenômeno humano, entre um indivíduo e outro, e não entre a linguagem e o mundo:

[...] uma das características do signo frequentemente evocadas pela linguística de filiação saussuriana é o fato de as diversas línguas naturais estabelecerem, cada qual para seu próprio uso, diferentes estruturações do "mundo" por elas concebido. Por isso, nessa perspectiva, tanto o polo da "palavra" quanto o do "conceito" são variáveis segundo a inserção sócio-histórica das expressões que estejam em pauta; consequência disso, entre outras, é ter de admitir que não existem jamais traduções exatas em duas línguas. (PIETROFORTE; LOPES, 2011, p. 116)

Para exemplificar essa questão, Pietroforte e Lopes (2011) usam o disco The dark side of the moon, da banda de rock britânica Pink Floyd. A capa do disco contém um arco-íris saindo decomposto de um prisma que é atravessado por um raio de luz branca. $\mathrm{O}$ arco-íris, no entanto, continha apenas 6 cores, não as 7 que nós, brasileiros, esperaríamos. E a razão para isso é que, no inglês, o purple engloba as cores que denominamos de roxo e anilado. Isso prova que a maneira de ver o mundo varia de uma cultura para outra, sem que se possa apontar quem está com razão na história.

Não é preciso, no entanto, ir tão longe e comparar duas línguas para se perceber que a maneira de ver o mundo varia. É possível notar isso numa mesma comunidade linguística e é o que Steiner (1992) defende em seu texto. Ilustrando: houve, recentemente, no Brasil, a destituição da presidente democraticamente eleita Dilma Rousseff, do Partido dos Trabalhadores (PT), cujas ideologias são de esquerda. Desde o início do processo, a presidente em questão passou a designar publicamente o ato como um golpe. As oposições políticas, então, também passaram a usar esse termo, mas com outra significação. Assim, a palavra golpe no atual contexto político brasileiro tem sido vociferada de um lado a outro, tendo sentidos totalmente contrários. Tomemos, a título de exemplo, a chamada de uma 
notícia intitulada $O$ golpe do golpe, veiculada na revista Veja, cuja linha ideológica é a dos partidos de direita no Brasil:

Se aqui dentro não colou, quem sabe lá fora. Na quarta-feira, a presidente Dilma Rousseff acordou convencida de que havia tido uma grande ideia. Iria, sim, ao encontro de chefes de Estado em Nova York para a cerimônia da Organização das Nações Unidas (ONU) de assinatura de acordos de meio ambiente firmados na conferência do clima de Paris. Lá, usaria o discurso a que tem direito, marcado para sexta-feira, para dizer ao mundo que o processo de impeachment a que responde é um "golpe" perpetrado por seus adversários contra ela e contra a democracia. Dilma chegou a cancelar a viagem depois da votação da Câmara que, por 367 votos contra 137 (mais sete abstenções e duas ausências), determinou o prosseguimento do processo. Em seguida, porém, mudou de ideia. Passou a achar que o púlpito da ONU, palco da diplomacia global, seria um ótimo palanque para ela repisar o argumento do golpe, já rejeitado no Brasil - pelos congressistas no dia 17 e bem antes pelos ministros do Supremo Tribunal Federal (STF), para ficar apenas no âmbito dos poderes constituídos. ${ }^{1}$

Em comparação, segue, abaixo, a chamada de uma notícia veiculada na revista Caros Amigos, cujo público receptor tem ideologias mais esquerdistas:

Vamos dar nome aos bois. O que aconteceu no Brasil, com a destituição da presidente eleita Dilma Rousseff, foi um golpe de Estado. Golpe de Estado pseudolegal, "constitucional", "institucional", parlamentar ou o que se preferir. Mas golpe de Estado. Parlamentares - deputados e senadores - profundamente envolvidos em casos de corrupção (fala-se em $60 \%$ ) instituíram um processo de destituição contra a presidente pretextando irregularidades contábeis, "pedaladas fiscais", para cobrir déficits nas contas públicas - uma prática corriqueira em todos os governos anteriores! Não há dúvida de que vários quadros do PT estão envolvidos no escândalo de corrupção da Petrobras, mas Dilma não... $\mathrm{Na}$ verdade, os deputados de direita que conduziram a campanha contra a presidente são uns dos mais comprometidos nesse caso, começando pelo presidente da Câmara dos Deputados, Eduardo Cunha (recentemente suspenso), acusado de corrupção, lavagem de dinheiro, evasão fiscal etc. ${ }^{2}$

\footnotetext{
${ }^{1}$ Disponível em $<$ http://veja.abril.com.br/brasil/o-golpe-do-golpe/ $>$. Acesso em $30 \mathrm{de}$ agosto de 2017.

${ }^{2}$ Disponível em $<$ http://www.carosamigos.com.br/index.php/artigos-e-debates/6891michael-loewy-o-golpe-de-estado-de-2016-no-brasil>. Acesso em 30 de agosto de 2017.
} 
É possível perceber com esses simples exemplos como o termo golpe é tomado pela revista Veja (que, nesse caso, é da oposição) e usado contra a presidente Dilma que antes o proferiu. O sentido é subvertido e usado como uma arma contra o adversário. Já o mesmo termo, na revista Caros Amigos, foi usado pensando-se em reforçar a significação primeira pensada pela presidente. Ou seja, o mesmo item lexical varia de significado num nível quase antitético devido a ideologias em competição. A questão que fica é: é possível pensar num significado verdadeiro? Se levarmos em consideração o pensamento saussuriano, não. Afinal, os sentidos são construídos pelo ser humano. A verdade, assim, também é uma construção dos homens e, por assim ser, é cambiante, instável e sujeita a controvérsias. Um público que compartilha as ideologias que perpassam os discursos produzidos e reproduzidos pela revista Veja pode aceitar o termo golpe lá utilizado como o verdadeiro, do mesmo modo que o faz um leitor da Caros Amigos. Retornamos, então, à antiga seara sofistica: a significação é construída a partir circunstância oportuna e dos saberes compartilhados e não há termos verdadeiros ou falsos, e, sim, preferíveis e desejáveis.

Desse modo, por estarmos sujeitos a uma linguagem porosa, opaca, que não nos permite acessar as coisas no mundo tais quais elas são, estamos sujeitos aos enganos e aos desencontros. Não há como termos controle dos efeitos causados por qualquer enunciação, pois, quando ela deixa seu estágio primeiro de atividade mental e é exteriorizada, quando cai no domínio da vida pública, não há garantias de que os efeitos pretendidos sejam, de fato, causados. E é a partir disso que Steiner (1992) afirma que o ser humano realiza um ato de tradução, no sentido completo da palavra, quando recebe uma mensagem verbal de qualquer outro ser humano:

[...] o modelo "emissor para receptor" que representa qualquer processo semiótico e semântico é equivalente ontologicamente ao modelo "língua de partida para língua de chegada" usado na teoria da tradução. Em ambos os esquemas, há "no meio" uma operação de decifração interpretativa, uma função codificadoradecodificadora, uma sinapse. Lá onde duas ou mais línguas se encontram numa interconexão articulada, as barreiras no meio serão claramente mais salientes e o empreendimento da inteliligibilidade mais consciente. Mas os "movimentos do espírito", para usar a frase de Dante, são rigorosamente análogos. São também assim, como veremos, as mais frequentes causas de mal-entendidos ou, o que é a mesma coisa, do insucesso em se traduzir corretamente. Em suma: entre línguas ou no interior de uma língua, a comunicação humana é igual à tradução. Um estudo da tradução é um estudo da linguagem (STEINER, 1992, p. 72). 


\section{CONSIDERAÇÕES FINAIS}

Steiner (1992) afirma no final de seu capítulo que o fato de que milhares de línguas diferentes e mutualmente incompreensíveis foram e são faladas em nosso planeta é uma expressão clara do enigma profundo da individualidade humana, da evidencia biogenética e biossocial de que não existem dois seres humanos inteiramente iguais. Não havendo dois seres humanos inteiramente iguais, a comunicação passa a ser, então, uma tradução. Desse modo, o presente trabalho teve como objetivo esboçar algumas teorias linguísticas que corroboram a tese de Steiner de que, no fundo, o processo de comunicação é equivalente ao processo de tradução. Seja por questões sociais ou questões puramente linguístico-cognitivas, o ser humano está fadado a traduzir mensagens de outros sujeitos, ainda que no interior de sua própria comunidade linguística.

\section{REFERÊNCIAS}

BELINE, Ronald. "A variação linguística". In: FIORIN, José Luiz (Org.). Introdução à linguística I: objetos teóricos. São Paulo: Contexto, 2011.

BÍBLIA. A. T. "Gênesis". Português. Bíblia sagrada: contendo o antigo e o novo testamento. Tradução João Ferreira de Almeida. Rio de Janeiro: Sociedade Bíblica do Brasil, 1966.

FIORIN, José Luiz. "Teoria dos signos”. In: FIORIN, José Luiz (Org.). Introdução à linguística I: objetos teóricos. São Paulo: Contexto, 2011.

HOOKS, Bell. Linguagem: ensinar novas paisagens/novas linguagens. Revista Estudos Feministas, pp. 857-864, set./dez., 2008.

JAKOBSON, Roman. "On linguistics aspects of translation". In VENUTI, Lawrence (ed.). The translations studies reader. London/New York: Routledge, 2004, pp. 113-118.

PAIVA, Maria da Conceição. "A variável gênero/sexo". In: MOLLICA, Maria Cecília; BRAGA, Maria Luiza (orgs.). Introdução à sociolinguística: o tratamento da variação. São Paulo: Contexto, 2004.

PIETROFORTE, Antônio Vicente Seraphim; LOPES, Ivã Carlos. "A semântica lexical". In: FIORIN, José Luiz (Org.). Introdução à linguística II: princípios de análise. São Paulo: Contexto, 2011, pp. 111 - 136.

SAUSSURE, Ferdinand. Curso de linguística geral. 26ª ed. Tradução Antônio Chelini, José Paulo Paes e Izidoro Blikstein. São Paulo: Cultrix, 1995 
SOUZA, Ana Alexandre Alves de; PINTO, Maria José Vaz. Sofistas: testemunhos e fragmentos. Lisboa: Imprensa Nacional - Casa da Moeda, 2005.

STEINER G. After Babel: aspects of language and translation. Segunda edição: Oxford, Oxford University Press, 1992.

Naaman Mendes Lataliza

namanmendes@yahoo.com.br

Recebido em: 9/9/2017

Aceito em: 7/2/2018

Publicado em Abril de 2018 